\title{
Internal Relationship between Education on Cultural Confidence and Cultural Consciousness
}

\author{
Ze Wei* \\ School of Marxism, Ningxia University, Yinchuan 750021, China \\ *Corresponding author: Ze Wei, 1ly1985@126.com
}

\begin{abstract}
Education on cultural confidence is the main way to strengthen one's cultural confidence while cultural consciousness constitutes a base for cultural confidence. The two would be unified in the process of strengthening cultural confidence. Therefore, there is a logical relationship between them. In order to understand the relationship between education on cultural confidence and cultural consciousness, one needs to have a correct understanding of the scientific connotation of the two and a clear picture that education on cultural confidence would ensure that one would be kept steadfast in cultural consciousness because it does not only establish attitudes in cultural conscious cognition but also act as a guide for internal development.
\end{abstract}

Keywords: Cultural confidence; Education on cultural confidence; Cultural consciousness

Publication date: October 2021; Online publication: October 29, 2021

\section{Introduction}

Education on cultural confidence is a practical activity that drives one to establish firm cultural confidence. It is the main way of helping an individual to master the contents and values of traditional fine Chinese culture, revolutionary culture, the advanced socialist culture, and core socialist values. Cultural confidence in contemporary China is by no means the universal confidence in any civilization or culture but rather it specifically points at the confidence in culture under the context of socialism with Chinese characteristics. In order to have a correct cognition of this culture and foster its permeation both in mind and action, cultural consciousness should be regarded as an inseparable part of it. In this sense, the cultivation of firm cultural confidence could not be without cultural consciousness and education on cultural confidence. Generally, the education on cultural confidence has a function of laying a solid cognitive foundation in ones' cultural consciousness to help establish one's cognitive attitude and guide the formation of one's cognitive attitude on culture. Hence, education on cultural confidence plays a key role in strengthening cultural confidence.

\section{Scientific connotation of education on cultural confidence and cultural consciousness}

The understanding of concepts is often seen as a starting point in theoretical research. To begin, there should be a clarification of the concepts in order to provide an explicit explanation of the internal relationship between the education on cultural confidence and cultural consciousness. Answering questions such as "What is cultural confidence?", "What is education on cultural confidence?", and "What does cultural consciousness mean?", understanding the concepts, as well as knowing their values, logical relations, and intrinsic values of the time is of great significance in understanding the relationship between education on cultural confidence and cultural consciousness. 


\subsection{Connotation of cultural confidence}

The spiritual power of culture runs through the historical production and life of humans. The prosperity of a nation or a country is inseparable from the nation's full understanding, firm recognition, and strong confidence of its own culture. The word "cultural confidence" here implies one's active mental state, one's rational and objective mentality on culture, as well as one's affirmation of ideals and values. It also implies one's firm conviction on cultural spirit, cultural ability, culture creation and development, and cultural values. Unlike the general sense of cultural confidence, the term "cultural confidence" here reflects one's strong affirmation and lythe firm holding ontoon to the cultural concepts, wills, spirits, and values under the context of socialism with Chinese characteristics. According to Oxford Advanced Learner's EnglishChinese Dictionary, the word "confidence" means having a firm trust in something or having a solid foundation for something. Hence, cultural confidence refers to a kind of confidence in culture under the context of socialism with Chinese characteristics. The steadfastness of cultural confidence is the accumulation of the spiritual pursuit and the standard of behavior of the Chinese nation. It embodies extensive patriotic enthusiasm and national feelings. It is also the essence in promoting the integration of Chinese civilization into the world civilization and in enhancing cultural exchanges and friendships among people. With the traditional fine Chinese culture along with the revolutionary culture and the advanced socialist culture as its substantial essence, cultural confidence reflects one's steadfastness, belief, affirmation, perseverance, and tenacity of the Chinese culture. It also refers to one's full confidence in the path, theory, system, and cultural achievements of socialism with Chinese characteristics. In short, cultural confidence acts as a spiritual guidance in realizing the grand dream of the Chinese people for national rejuvenation. It is not only a spirit but also an encouragement in promoting the creation of a new brilliant culture that contributes "the Chinese wisdom" or "the Chinese plans" to the world.

\subsection{Connotation of education on cultural confidence}

"Education is of fundamental importance to the fulfillment of our great long-range mission," said Xi Jinping, the General Secretary of the Communist Party of China (CPC), during the one-year anniversary of The UN Global Initiative on Giving Priority to Education that was held on September 25, $2013^{[1]}$. At a symposium with the faculties of Beijing University held on May 2, 2018, Xi Jinping once again stressed the importance of education, where he mentioned, "The country prospers if education prospers; the country is strong if education is strong [2]." Clearly, education plays a fundamental role in national thriving and social advancement. In time when socialism with Chinese characteristics enters a new stage, the education on cultural confidence should be underscored as it is conducive in cultivating cultural confidence, promoting socialist cultural thriving, and constructing a culturally powerful socialist country. Education on cultural confidence is, in essence, an education on values of concepts. It is a high degree of confidence which one holds on to in culture and values developed through history and practical activities. Through such an education, one would endorse or approve this culture or civilization. In a sense, education on cultural confidence is the key element in ideological and political education.

\subsection{Connotation of cultural consciousness}

The concept "cultural consciousness" was first introduced by Professor Fei Xiaotong, a well-known sociologist, at the end of the last century. According to Professor Fei, cultural consciousness refers to (a) person/people living under a certain cultural background having a clear understanding of his/her/their cultural origin, formation process, characteristics, and development trend; reversely, it does not mean "cultural return," "retro to the past," nor does it mean "total westernization" [3]. The prerequisite for cultural consciousness lies in one's "self-knowledge." The term "self-knowledge" is by no means an empty 
awakening, rather it requires rational guidance. It means one can achieve "self-knowledge" via cognition. Similarly, the base of cultural consciousness is cultural internalization, which refers to a stable, independent, lasting, and dynamic ability of value judgment. Hence, possessing the ability of value judgement means possessing cultural internalization. Cultural consciousness is the key element to cultural confidence. Usually, it requires a long time for the development or evolution of "cognition - self-knowledge internalization - consciousness"; thus, it is safe to say that it is often the "education on cultural confidence" that works.

\section{Internal relationship between education on cultural confidence and cultural consciousness}

\subsection{Education on cultural confidence lays a cognitive foundation for cultural consciousness}

The prerequisite for developing cultural consciousness is to allow people to have a rational, objective, and complete understanding of their own culture; that is, to have a cognition of their own culture. Hence, cultural cognition reflects an individual's accurate cognition of the traditional Chinese culture, its cultural values, and the cultural connotation. It refers to people's clear understanding of the historical context, content system, creative subject, and value implication of the Chinese culture. The understanding and grasping of the Chinese culture is a process in comprehensive study. The key question in cultural cognition is "What Chinese culture is?". This is a premise for an individual to be conscious of his or her own culture. Education on cultural confidence is an important pursuit in laying the foundation for cultural conscious cognition. It is beneficial to ensure the accuracy of people's understanding of traditional fine Chinese culture, promote the inheritance of this culture, understand the unique outlook on life, values, nature, and philosophy of the Chinese nation, as well as fully absorb cultural nutrients to firmly grasp the connotation and core meaning of the traditional fine Chinese culture. It is also beneficial to encourage the accurate understanding of the Chinese revolutionary culture and the continuation of the revolutionary spirit, inherit the advanced culture created by the $\mathrm{CPC}$ and the Chinese people during the long-term revolutionary struggle, as well as urge the maintenance of the revolutionary spirit and will in struggling so that the people can accomplish their original mission. In addition, it is beneficial to ensure the correct cognition of advanced socialist culture, enable people to recognize the advanced Chinese socialist culture, drive the active practice of socialist core values, learn and absorb from foreign cultures, as well as maintain the internal vitality of the culture itself.

Obviously, cultural cognition is the premise and foundation of cultural consciousness. Only through education on cultural confidence along with a comprehensive and accurate content indoctrination and value guidance, people would be able to solidly master the knowledge system of socialist culture with Chinese characteristics. Till then, the content of such an education should be internalized to achieve the final goal of cultural consciousness.

\subsection{Education on cultural confidence establishes an identity for cultural consciousness}

If cultural cognition is the prerequisite and foundation of cultural consciousness, then cultural identity is its key. This is because cognition may not necessarily form an identity. The formation of consciousness must be based on accurate cognition and a high degree of consensus from the heart. Cultural identity does not only refer to people's identity but also to the value identity of the cultural environment. The former emphasizes on the society's recognition of the identity of the Chinese nation, while the latter refers to the affirmation of the content system, ideological system, and value system of the culture under the context of socialism with Chinese characteristics. The two are unified in the recognition, praise, and firm attitude of the people toward culture. Therefore, the education on cultural confidence is the key in enabling people to establish their national and cultural identity. The establishment of national identity is an important mission 
in the education on cultural confidence as it strengthens people's consciousness in building a Chinese national community. It does not only cultivate people's attitude toward the membership of the Chinese national community in which they are living, but also their respect and praise toward the history of Chinese civilization as well as the excellent cultural achievements.

The establishment of cultural identity is to enable people to accurately grasp the logical order and development law of socialist culture with Chinese characteristics, build the general consensus on socialist core values, as well as guide people to maintain mutual appreciation and inclusiveness in order to preserve one's own culture while exchanging and absorbing from other excellent cultures. The purpose of maintaining and exchanging is to appreciate the values of others as do to one's own, and via such appreciation, the world would become a harmonious whole ${ }^{[4]}$.

\subsection{Education on cultural confidence provides a path for internalization of cultural consciousness}

The internalization of a culture is a dynamic input, which can be realized by people's cultural perception. It is based on cultural cognition and cultural identity. It is a unified, stable, and long-lasting value system that is deeply embedded in people's minds and hearts. The degree of internalization depends on whether such a cultural cognition is comprehensive and accurate, and whether keeping such cultural identity is firm or stable. Only by establishing an accurate cognition and firm identity, then it can be reflected as consciousness. In guiding people to cultivate internalization and maintain consciousness of the culture under the context of socialism with Chinese characteristics, the key is to mobilize people's enthusiasm and respect individual differences.

Firstly, in mobilizing people's enthusiasm, the focus should be on the innovation of education content. In view of the peculiarity of culture, different ways should be adopted while imparting culture as the main purpose of the education is to build a firm confidence in culture under the context of socialism with Chinese characteristics, encourage people to master the law of cultural development, and promote the combination of education with practical work in order to raise a powerful country. The attraction of the education depends on the continuous innovation of the education content. For example, in regard to traditional fine Chinese culture education, the focus should be on showing its perspectives in creation, innovation, and transformation; in regard to revolutionary culture education, its red resources and tenacious revolutionary spirit should be explored; in regard to advanced socialist culture education, its distinct scientific nature, advanced nature, and epochal character should be carried forward, while its socialist core values should be cultivated. Using these methods, the effectiveness of education on cultural confidence can be uplifted.

Secondly, in cultural education, individual differences should be respected. It is often a rule that education should be carried out in accordance with students' aptitude, and the most important aspect in education is the respect toward objective law and principle. Usually, people are different in terms of their educational level and their ability to accept; therefore, in order to respect individual differences, the methods of teaching should be modified to suit the requirements of each group. In order to develop people's subjectivity, independence, and initiative skills in cultural education, it is essential to create a harmonious, equal, and pleasant environment. On the basis of acknowledging individual differences, it is necessary to guide people, both scientifically and reasonably, to recognize the education content, cultivate cultural identity, and eventually realize the goal of internalizing cultural values.

\section{Disclosure statement}

The author declares that there is no conflict of interest. 


\section{References}

[1] Xi J, 2018, On Governance of China (Volume 1), Foreign Languages Press, Beijing, 191.

[2] Xi J, 2018, Speeches at the Symposium with Faculties at Beijing University, People's Daily.

[3] Fei X, 1997, Retrospect, Dialogue and Cultural Conscientiousness. Journal of Beijing University (Philosophy and Social Sciences Edition), (03): 15-22, 158.

[4] Fei X, 2013, Globalization and Cultural Consciousness, Foreign Languages Education and Research Press, Beijing, 66. 